the mediator ( 36 cases did not have a surface subject).

The fifth hypothesis was that items would be recalled better if they were incorporated as whole lexical items into the sentence or NLM than if they were embedded in other words. According to this prediction, BUN-TOG should be recalled better when the memory device was "She wore a BUN on her TOGs" than when it was "The BUNny worked the TOGgle switch." An additional transformation of information, in part semantic and phonetic, is necessary when the item is embedded in a different word. If the transformation is not recalled, then correct recall of the memory device is useless. There was some support for this proposition, in that $56 \%(55 / 99)$ of the items that retained their integrity were correctly recalled as opposed to $30 \%$ (12/44) of the items that were combined into larger words $(\mathrm{p}<.01)$.

\section{DISCUSSION}

Although the results confirmed those of other investigators in that items for which a mediator was reported were recalled significantly better than other items ( $55 \%$ to $14 \%$, respectively), linguistic structure did not have a consistent or strong influence on recall. No differences were obtained between the sentence and the NLM groups, which indicates that the instructions exerted no differential constraining effects upon the Ss. However, the inconsistency with which grammatical form relates to the effectiveness of a mediator casts doubt upon the primacy of linguistic variables in the formation of memory devices. It follows that the label of NLM is something of a misnomer unless it is intended to refer only to the means by which a memory device is communicated to an observer.

Several explanations can be advanced for the failure of our predictions. First, perhaps the wrong linguistic relations were examined. This is quite possible, but it would be hard to find linguistic variables that are now considered more basic or more general. Second, the task or the verbal materials may be so artificial that they do not readily expose linguistic organization and processes in learning. It is quite possible that a learning task that was devised for studying S-R associations may not be suitable for studying the use of rules and cognitive structures. Third, it is by no means certain that the mediators that the Ss wrote down were, in fact, the mediators that they used-the reported memory devices may have possibly been generated in response to the task demands of the experiment and not utilized in learning the items.

However, because four of five results that we examined were in the predicted direction, we cannot discard the possibility that grammatical structures play a role in the elaboration of memory devices, albeit not a primary one. Having raised the issue of the role of syntactic structure in natural language mediation, we find it prudent to leave the question open.

\section{REFERENCES}

ADAMS, J. A. Human memory. New York: McGraw-Hill, 1967.

BITZER, D. L., HICKS, B., JOHNSON, R., \& LYMAN, E. R. The PLATO system: Current research and development. IEEE Transactions on Human Factors in Electronics, 1967, 8, 64-70.

DELIN, P. S. Learning and retention of English words with successive approximations to a complex mnemonic instruction. Psychonomic Science, 1969, 17, 87-89.

CHOMSKY, A. N. Aspects of a theory of syntax. Cambridge, Mass: M.I.T. Press, 1965.

MONTAGUE, W. E., ADAMS, J. A., \& KIESS, H. $O$. Forgetting and natural language mediation. Journal of Experimental Psychology, 1966, 72, 829-833.

MONTAGUE, W. E., \& KIESS, H. O. The associability of CVC pairs. Joumal of Experimental Psychology Monograph, 1968, 78, No. 2, Part 2.

MONTAGUE, W. E., \& WEARING, A. J. The complexity of natural language mediators and its relation to learning. Psychonomic Science, 1967a, 7, 135-136.

MONTAGUE, W. E., \& WEARING, A. J. Natural language mediation: $A$ source of interference with extra-experimental interference. Psychonomic Science, 1967b, 9, 317-318.

ROHWER, W. D. Constraint, syntax, and meaning in paired-associate learning. Journal of Verbal Learning \& Verbal Behavior, 1966, 5, 541-547.

WEARING, A. J., WALKER, K. B., \& MONTAGUE, W. E. Recall of paired associates as a function of their associability. Psychonomic Science, 1967, 9, 533-534. NOTES

1. This research was supported in part by the Joint Services Electronic Program (U.S. Army, U.S. Navy, and U.S. Air Force) under Contract No. DA 28043 AMC 00073(E); in part by ONR Nonr-3985(08); and in part by the Computer-based Educational Research Laboratory at the University of Illinois.

2. The authors are grateful to Rosemary Wearing, Linda Kalmanek, Marcia Harms, Valerie Kussler, Pamela Polson, Jillian Rewortz, and Barbara Larick for their assistance in the collection and analysis of the data presented here.

3. Please address all requests for reprints to Alexander J. Wearing, Yale University, Department of Psychology, 333 Cedar St., New Haven, Conn. 06510.

\title{
A test of the spew hypothesis using intralist repetition and a free-recall task ${ }^{1}$
}

\section{SHARRON S. WIKE and EDWARD L. WIKE, University of Kansas, Lawrence, Kans. 66044}

The role of intralist repetition on free recall was investigated using 43 college students. In each of four lists, 5 words were repeated three times each and 15 words were given once. The same 20 words were used for all four lists, but the words that were repeated varied across lists. It was found that during output the repeated words had significantly higher mean position than did the nonrepeated words. The result agreed with the spew hypothesis of Underwood \& Schulz, (1960).

According to the spew hypothesis of Underwood \& Schulz (1960), the order of output of verbal items is related to the frequency of input. It is assumed that more frequently experienced verbal items are more available and are recalled sooner than less frequently experienced items.

Underwood and Schulz found support for this hypothesis in a number of studies (e.g., Brown, 1915; Cromwell, 1956; Johnson, 1956; Howes, 1957) in which the frequency of occurrence was established outside the laboratory. In Experiment 1 (Underwood and Schulz), frequency was manipulated experimentally and output was measured in free recall. The $S$ was given familiarization training on 40 low-association-value nonsense syllables. The $\mathrm{S}$ was exposed to a given syllable 40 , 20,10 , or 1 time and was instructed to spell the syllable upon each exposure. At different intervals during the familiarization training, $S$ had five test 
Table 1

Subsets of Words Repeated for a Given List

\begin{tabular}{llll}
\hline Subset A & Subset B & Subset C & Subset D \\
\hline payroll & government & spray & help \\
early & velvet & zebra & legal \\
arithmetic & turtle & typical & family \\
lake & possible & arrow & delicious \\
theory & enemy & tonight & insurance \\
\hline
\end{tabular}

trials in which he liad to fill in one missing letter from each syllable on a printed sheet. Errors were corrected by E. A free recall task followed this familiarization/test-trials training. The $S$ was instructed to write all the syliables he could remember. In support of the spew hypothesis the authors reported, "Of the first three syllables the subject gave during free recall, $43 \%$ were syllables which had been presented 40 times, 33\% 20 times, 22\% 10 times, and 2\% 1 time [p. 104]." Thus, when frequency of experience with nonsense syllables was experimentally manipulated, the results of the Underwood and Schulz study implied that the order of output in a free recall task was related to frequency of input.

The present study manipulated frequency of input in a free recall task and measured order of output for two different frequencies. This study differed from the Underwood and Schulz experiment in a number of ways: (1) Words were used as material rather than nonsense syllables; (2) there were no test trials interspersed during learning; (3) words were presented 3 or 1 time vs $40,20,10$, and 1 time in the Underwood and Schulz study; and (4) the mean positions on total output for repeated vs nonrepeated syllables were compared as contrasted with the Underwood and Schulz study in which only data for the first three syllables recalled were presented. Thus, the aim of the present experiment was to assess the generality of the spew hypothesis under conditions that differed greatly from those of Underwood and Schulz.

\section{METHOD}

The Ss were 43 volunteers, 18 males and 25 females, from the introductory psychology course at the University of Kansas. The Ss were tested in groups of 10 to 12. The group receiving List $A$ had $10 \mathrm{Ss}$, the group receiving List $\mathrm{B}$ had $10 \mathrm{Ss}$, the group receiving List $\mathrm{C}$ had $12 \mathrm{Ss}$, and the group receiving List D had $11 \mathrm{Ss}$. All four groups were tested in the morning and in the afternoon of one day.

The material consisted of 20 common words, randomly divided into four subsets of five words each. The four subsets, A, B, $C$, and $D$, are presented in Table 1 . For List A, the Subset A was the words that were presented three times in the free recall task and the remaining words in Subsets B, C, and D were presented once.
For List B, the Subset B was the words that were presented three times and the remaining words in Subsets A, C, and D were presented once. The same general plan was followed for Lists C and D. Each list contained the same 20 words. Thus, a total of 30 items was presented in the free recall task -5 items were repeated three times and 15 items were repeated once.

The order of the 30 items was randomly determined for each list. As items from the items from the first of the list tend to be recalled next, and items from the middle of the list tend to be recalled last (Deese \& Kaufman, 1957), the lists were checked to see if there was an approximately even distribution of repeated vs nonrepeated words at the beginning and end of the lists. Over the four lists, $40 \%$ of the first five words were repeated words and $60 \%$ were nonrepeated words; $50 \%$ of the last five words were repeated words and $50 \%$ were nonrepeated words. Forty-seven and one-half percent of the first 10 words were repeated words and $47.5 \%$ of the last 10 words were repeated words.

The task-instructions and material-was presented by a tape recorder. There were four tapes, one for each list. The instructions were identical for all four lists. The items were delivered at approximately a 4-sec rate. The instructions were as follows: "This is a learning experiment. I will read a list of words. Try to remember as many of the words as you can. After all of the words have been spoken, you will be instructed to write down all the words you can remember. They can be in any order. You will be given five minutes to write the words. Are you ready? Listen. The following are the words you are to remember." The list was then presented. Following the list, the instructions continued: "This finishes the list. At the top of the paper write your name, whether you are a male or a female, and write Experiment '__ (A, B, C, or D). Then write down as many of the words in the list as you can remember. They can be in any order."

In the scoring of the recall protocols, if a word was listed that was not on the list or a word that was on the list was listed more than once, that word was crossed out, and remaining words were each moved up one position. last of the list tend to be recalled first,
RESULTS AND DISCUSSION

The measure of order of output of the repeated and nonrepeated words used for each $S$ was the mean position of the repeated words vs the mean position of the nonrepeated words that were recalled. If no law is operating, if output order is determined just by chance, one would expect the same mean position on output for the repeated and nonrepeated words. For example, if seven words were recalled, it would be expected that the mean position of the repeated words would be four and the mean position of the nonrepeated words would be four. If, however, $S$ is responding according to the spew hypothesis, then the mean position output of the repeated words should be lower than the nonrepeated words.

The data were submitted to a 4 by 2 repeated measurements analysis of variance design. The four-level factor was list and the two-level factor was repetition. Neither lists nor Lists by Repetition was significant. Repetition was significant $(F=20.89, \mathrm{df}=1 / 39, \mathrm{p}<.001)$. The mean position on output for the repeated words (4.24) was significantly lower than the nonrepeated words (5.65).

In agreement with the results of the Underwood and Schulz study, of the first three words that were recalled, $60 \%$ were repeated words and $40 \%$ were nonrepeated words.

The results of this study offer additional support for the spew hypothesis. It was found that words that have a higher experimental frequency tend to be output sooner than words that have a lower experimental frequency. This result agrees with previous studies in which frequency differences have been established outside the laboratory and in which differences have been established experimentally.

\section{REFERENCES}

BROWN, W. Incidental memory in a group of persons. Psychological Review, 1915, 22, $81-85$

CROMWELL, R. L. Factors in the serial recall of names of acquaintances. Journal of Abnormal \& Social Psychology, 1956, 53, 63-67.

DEESE, J., \& KAUFMAN, R. A. Serial effects in recall of unorganized and sequentially organized verbal material. Journal of Experimental Psychology, 1957, 54, 180-187.

HOWES, D. On the relationship between the probability of a word as an association and in general linguistic usage. Journal of Abnormal \& Social Psychology, 1957, 54, 75-85.

JOHNSON, D. M. Word-association and word-frequency. American Journal of Psychology, 1956, 69, 125-126.

UNDERWOOD, B. J., \& SCHULZ, R. W. Meaningfulness and verbal learning. New York: Lippincott, 1960.

NOTE
1. These studies were supported by a grant HD 00870, from the National Institute of Child Health and Human Development and a Biomedical Sciences Support grant, FR-07037. 